Portland State University

PDXScholar

2-23-1976

\title{
A Test of Conservation for Continuous and Discontinuous Quantity in the Very Young Child
}

Nancy Patrick Kaye

Portland State University

Follow this and additional works at: https://pdxscholar.library.pdx.edu/open_access_etds

Part of the Psychology Commons

Let us know how access to this document benefits you.

\section{Recommended Citation}

Kaye, Nancy Patrick, "A Test of Conservation for Continuous and Discontinuous Quantity in the Very Young Child" (1976). Dissertations and Theses. Paper 2363.

https://doi.org/10.15760/etd.2360

This Thesis is brought to you for free and open access. It has been accepted for inclusion in Dissertations and Theses by an authorized administrator of PDXScholar. Please contact us if we can make this document more accessible: pdxscholar@pdx.edu. 
AN ABSTRACT OF THE THESIS OF NanCY Fatrick Kaye for the Master of Science in Psychology presented February 23, 1976.

TITLE: A Test of Conservation for Continuous and Discontinuous Quantity in the Very Young Child.

APPROVED BY MEMBERS OF THE THESIS COMMITTEE:

Gerald Guthrie, Chairman

Barry Ánderson

David Cressier

Nancy Marshall

The development of mathematical concepts in children has been studied by many researchers. Much of this research has focused on the concept of conservation which was introduced by Piaget. It has generally been assumed that children under the age of five years are not capable of such conservation. Some recent evidence suggests that children under this age do conserve on particular tasks. In this study one hundred children from age two years four months to three years seven months were tested for conservation of 
discontinuous and continuous quantity. Although some evidence of conservation in this age range was obtained, no consistent pattern emerged. An edible dough was used, so that both verbal (noneating) and nonverbal (eating) responses were recorded for children of these ages. A three-factor. analysis of variance showed that there were no significant effects from age, eating/noneating, or continuous/discontinuous variables. However, there was a significant but puzzling interaction between the continuous/discontinuous and eating/noneating factors. 


\title{
A TEST OF CONSERVATION
}

FOR CONTINUOUS AND DISCONTINUOUS QUANTITY

IN THE VERY YOUNG CHILD

\section{by}

Nancy Patrick Kaye

A thesis submitted in partial fulfillment of the requirements for the degree of

\author{
MASTER OF SCIENCE \\ in \\ PSYCHOLOGY
}

\author{
Portland State University \\ 1976
}


TO THE OFEICE OF GRADUATE STUDIES AND RESEARCH:

The members of the Committee approve the thesis of Nancy Patrick Kaye presented February 23, 1976.

Gerald Guthrie, Chairman

Barry Ahderson

David Cressler

Nancy Marshall

APPROVED :

Robert Jones

Head, Department of Esychology

Richard B. Halley

Dean of Graduate Studies and Research 
TABLE OF CONTENTS

PAGE

LIST OF TABLES • • • • • • • • • • • • • j.V

LIST OF FIGURES • • • • • • • • • • • • • • V v

INTRODUCTION • • • • • • • • • • • • • • 1

METHOD . . . . . . . . . . . . . . . 6

Subjects and Setting . . . . • . 6

Procedure

RESULTS • • • • • • • • • • • • • • • 11

SUMMARY AND CONCLUSIONS • • • • • • • • • $\quad 19$

BIBLIOGRAPHY • . . . . . . . . . . 21 


\section{LIS'Y OF TABLES}

TABLE

PAGE

I Number of Conserving Responses in each

Task

1.1

II Three-factor Analysis of Variance . . . . 13 


\section{LIST OF FIGURES}

FIGURE

PAGE

I Display of Discontinuous Presentation . 10

I Display of Continuous Presentation . . 10

II Noneating Responses . . . . . . . . 15

IV Eating Responses . . . . . . . . 3.5

$\mathrm{V}$ Total of Noneating/Eating Responses . . . 16

VI Discontiruous Responses . . . . . . 16

VII Continuous Responses • . . . . . . 17

VIII Total of Discontinuous/Continuous

Responses . . . . . . . . . • . 17

IX Interaction of Continuous/Discontinuous and Eating/Noreating Responses . . . 1.8 


\section{INTRODUC'TION}

The development of mathematical concepts in children has been studied by many researchers (Piaget 1952; Bruner 1967: Iove11 1961). Most studies have centered on basic number concepts such as cardination, ordination and addition or on conservation of particular properties such as quantity, weight, area, and volume.

Jean Piaget has done most of the work on the development of mathematical concepts in chilären (Piaget 1952, 1953; Piaget et. al. 1960). Most investigations in this area employ Piaget's notion of conservation and some adopt the tests which Piaget used. By "conservation", Piaget means the comprehension that a property of an object or substance has not changed when other properties or relations have been altered or certain operations have been performed. He identifies three stages in the development of conservation. Stage I is the absence of conservation. Stage II is an intermediate stage in which conservation begins to develop, but the child stjll trusts his naive perceptions. In Stage III the child is "able to coordinate his perceptions with conservation." This final stage j.s characterized by the child's unfaltering recognition of a conserved quantity. It should be noted that for each task fiaget studies, such as measurement of quantity, area, weight, length or volume, he varies slightly the definition of each stage, but the above description of the three stages corresponds generally to 
Piaget's specific description of conservation development. According to Piaget, this stage development is highly dependent on age. He states that a child under the age of five is in an egocentric stage and unable to conserve. At about age five, he suggests, children are able to develop conservation of continuous and discontinuous quantity or number. For other tasks the child is not able to conserve until a later age, the age increasing with the difficulty of the task.

Estes (1956) disputes Piaget's assertion that the stages are age related. Four of Piaget's problems were given to four, five, and six year olds. In each instance, Estes contends, her findings do not support Piaget's. For example, eight white chips were placed in various spatial arrangements, and the children were asked to take an equal number of red chips from a box. Estes found no stage development for this task. In general her findings for all her tests were: (a) that if children could count, they counted correctly whatever the arrangement of objects; (b) they did not confuse extension of a line with increase in number; (c) they did not mistake an apparent increase with a true increase in number, and (d) if they could project a straight line in one direction they could project it in another. Dodwell (1960) set out to retest some of Piaget's findings in light of Estes' work. In general, he supports Piaget, but finds that performance is not strictly 
correlated with age. In addition, Dodwell shows that the ability to count does not guarantee conservation. For example, when asked which of two lines of chips contained more chips, even children who would count the number of chips in each line often would choose the one which extended farther over the one with a higher number of chips.

Mehler and Bever (1967) investigated the ability of very young children to conserve. They pointed out that children under four years of age had never been tested, since children of this age were not expected to have developed conservation. Their study showed, however, that children between the ages of two years four months and three years two months do demonstrate conservation of quantity. Then, at about three years two months, the ability to conserve is lost until it is regained at about four years six months. They suggest this time period when conservation is temporarily lost represents a time when the child is overly dependent on perceptual cues.

The conservation task studied by Mehler and Bever involved one array consisting of two parallel lines one of which was made of four objects and the other of six objects. The six objects were spaced close together and the four objects were spaced farther apart so that the end points of the row with four objects extended beyond the end points of the row with six objects. Each array was presented using clay pellets in one instance and M\&M candies in the other. 
In all, there were a total of four presentations to each child. When the child was presented the clay pellet task he was asked which row had "more." In the task with M\&M's the child was told to "take the row you want to eat, and eat all the M\&M's in that row."

Results for the experiment showed that children under three years two months could conserve although the ability decreased after two years six months. The decrease was significant for verbal responses (the clay pellet task) but not for nonverbal responses (the M\&M task). Occasionally the child would respond one way for the clay pellet task and the other way for the M\&M task. If a child gave inconsistent responses it was significantly more likely that the conserving response was given on the M\&M task.

Mehler and Bever do not explain why children would choose the row with six M\&M's rather than four when told to "take the row you want to eat and eat all the M\&M's in that row." It appears the assumption is that children like M\&M's, want to eat as many as they can, and will, therefore, take the row they believe to have the greater number of M\&M's. Although the results do show that most children choose the row with six M\&M's significantly more often, there is no indication whether this result was due to the change in instructions from the clay pellet task to the M\&M task or whether the same effect would have been observed had the tester asked the child to state which row of M\&M's 
had more.

The reason for the significantly higher overall performance with the M\&M's is thus unknown; it may have been the result of differently phrased directions or it may have been due to the reinforcement value of the M\&M's as compared with the clay pellets. By altering the instructions, but using the same material, this study will determine whether modifying the instructions affects performance.

Piaget suggests that conservation of continuous and discontinuous number and quantity occur simultaneously at about five years of age. The test for conservation of a discontinuous quantity or number consists of asking a child if two configurations of discrete objects, that is, objects which the child can count, are the same number or amount. Conservation of continuous quantity involves material which is continuous and therefore can not be subdivided to enable counting. Again the child is asked if one configuration has the same amount or not:. Most studies only test for conservation of continuous or discontinuous quantity singly, and only the Mehler and Bever study examined conservation of discontinuous quantity in very young children. Both Estes (1956) and Mehler and Bever (1967), in studies with discrete materials, find conservation of discontinuous quantity at earlier ages than those suggested by Piaget. Since there has been no study of whether conservation of continuous quantity occurs at very young ages, this study will test 
conservation of both continuous and discontinuous quantity at these very young ages.

METHOD

Subjects and setting.

One hundred children of ages ranging from two years four months to three years seven months were used in this study. The children were divided into groups of 25 as follows:

$\begin{array}{cccccc}\text { Age } & \text { Group } & \text { Year } & \text { Month } & \text { through } & \text { Year } \\ 1 & 2 & 4 & & \text { Month } \\ 2 & 2 & 8 & 2 & 7 \\ 3 & 3 & 0 & 3 & 3 \\ 4 & 3 & 4 & 3 & 7\end{array}$

These age groupings include the conserving age ranges found in the Mehler and Bever study. Children were drawn primarily from various day care programs. If there was reason to believe that a child was of below average intelligence, the child was not tested. If the child refused to answer any question, his other answers were not used. Interviews were taped whenever possible.

\section{Procedure.}

Prior to administration of the tests, each child was asked to taste two kinds of cookie dough and indicate his preference. The type of dough so selected was used 
throughout the experiment with each child. The dough was formed into uniform pellets by using a small mold. SimilarIy, equal amounts of dough were rolled into strands for the continuous task.

In this study a correct response is the conserving response. Thus, an entry of 16 in Table I under Discontinuous/Noneating means that 16 out of 25 children gave the conserving response for this task. Although most children responded quickly, the instructions were repeated several times if necessary. The initial response which the child gave was used, unless he immediately changed his answer. In this case the question was repeated and the first response to the repeated question was used. Although it was stated that a correct response is a conserving response, strictly speaking the most that can be said is that a correct response is the response that would have been given had the child been conserving. A correct response on any one test is also consistent with the hypothesis that the correct choice was arrived at by guesswork or some other process. It is therefore necessary to test one child repeatedly or many children once. The latter approach is followed here.

The first experimental design tested for conservation of discontinuous quantity. The dough was prepared in pellet form and displayed to the child as two parallel lines, each composed of four equally spaced pellets (See Figure I a). 
The child was asked if the two lines were "the same." If he nodded or otherwise answered affirmatively, the test proceeded. If he answered negatively or did not respond, he was asked to make the two lines "the same."

The next presentation in this test for conservation of discontinuous quantity consisted of a long line of four pellets and a short line of six, more closely spaced pellets (See Figure I b). Each child observed the pellets' being rearranged. The child was again asked if the lines were the same. Regardless of the child's response, he was asked to point to the row with more dough. This comprised the noneating task. Then the two unequal iines of pellets were again presented, the child was told to take the row he warted to eat and to eat all the pellets in that row. This eating task elicited a nonverbal response.

The second experimental design tested conservation of continuous quantity. Two arrays of lines were again presented. But this time each line consisted of an elongated row of dough rather than a series of dough pellets. The first array consisted of two parallel lines of equal length (and amounts of dough). (See Figure II a). The child was asked if these lines were the same. If the child did not indicate that the rows were the same, he was asked to make the lines the same.

At this point, a second presentation was prepared. As the child watched, more dough was added to one Iine, and 
a)

b)

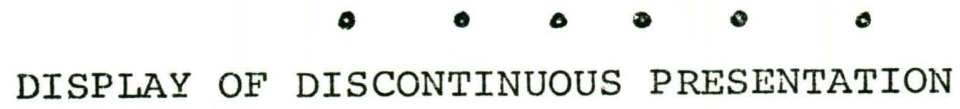

Figure I. a) First presentation. The length of the lines will be seven inches. b) Second presentation. The length of these lines will be seven inches and three inches.

a)

b)

\section{DISPLAY OF CONTINUOUS PRESENTATION}

Figure II. a) First presentation. The length of the lines will be four inches. b) Second presentation. The length of these lines will be four and two inches respectively. 


\section{RESULTS}

The number of conserving responses for each task is summarized in Table $I$.

TABLE I

NUMBER OF CONSERVING RESPONSES

IN EACH TASK

\begin{tabular}{cccccc}
\hline \multicolumn{4}{c}{ Discontinuous } & \multicolumn{3}{c}{ Continuous } \\
\hline & Non-eat. & Eat. & Non-eat. & Eat. & Total \\
\hline 1 & 16 & 14 & 19 & 12 & 61 \\
\hline 2 & 12 & 18 & 13 & 14 & 57 \\
\hline 3 & 8 & 14 & 11 & 15 & 48 \\
\hline 4 & 9 & 16 & 12 & 12 & 49 \\
\hline Total & 45 & 62 & 55 & 53 & 215 \\
\hline
\end{tabular}

From an examination of Table I it appears that the youngest children, those in Group 1, gave more conserving responses than any other group. Age Group 2 had the second highest total of conserving responses, followed by groups 3 and 4 whose scores were about the same.

When the total conserving responses listed in Table I are divided into eating and non-eating conserving responses, it becomes apparent that this overall inverse relationship between age and conservation pertained only to the non-eating tasks. On the eating tasks, the different age groups performed more or less the same.

Another indication of the relationship between age and conservation can be found from the number of children in 
each age group who consistently conserved. Each child gave four responses. In Group 1, eight children gave correct responses in all four cases; Group 2, only half that number or four children gave consistently correct answers; in Group 3 only one child and in Group 4, only two children responded correctly on all tasks.

Another difference in the performance of the youngest group and the others is while the responses for Group 1 in discontinuous/non-eating and discontinuous/eating are about the same, the responses for all the other groups are higher in the discontinuous/eating situation. On the other hand, in the continuous task the responses for groups 2, 3, and 4 stayed about the same in each task while they dropped for Group 1 in the eating task.

Figures III through VIII present the same data graphical.Iy with the abscissa representing the four age groups and the ordinate showing the number of correct responses. Figure IX shows the interaction of the eating/non-eating and continuous/discontinuous conditions.

The first basic question is whether any age group demonstrated conservation on any of the tasks. One-tailed binomial tests were used to determine if there were significant departures from a chance probability of making a conserving response. Only Group 1 on the non-eating/continuous task and Group 2 on the eating/discontinuous task demonstrated conservation by this test $(p<.05)$. Although the scores 
of the boys were significantly higher than chance $(p=.05)$, the difference between boys and girls was too small to show any significant relationship to sex.

A three-factor analysis of variance on repeated

measures was used to analyze the results further. This analysis is summarized in Table II.

TABLE II

THREE-FACTOR ANALYSIS

OF VARIANCE

Between Subjects
A (Groups)
Sub. within
groups
1.1875
96
.39583
1.246

Within subjects

$\begin{array}{rrrrr}\text { B (Dis/Cont.) } & .0025 & 1 & .0025 & .007 \\ \text { AB } & .2675 & 3 & .089 & .2596 \\ \text { B x subjects } & 32.98 & 96 & .344 & \\ \quad \text { within groups } & & & & \\ \text { C (Eat/Noneat) } & .563 & 1 & .5625 & 3.734 \\ \text { AC } & .228 & 3 & .076 & .503 \\ \text { C x subjects } & 14.46 & 96 & .151 & \\ \text { within groups } & & & .903 & 5.34 \\ \text { BC } & .903 & 1 & .043 & .252 \\ \text { ABC } & .128 & 3 & .169 & \\ \text { BC x subjects } & 16.22 & 96 & & \end{array}$

* significant at the .05 level

It indicates there is a significant difference for the interaction of the eating, noneating and continuous/ 
discontinuous factors $(p<.05)$. No other conditions were significant at the .05 level. 

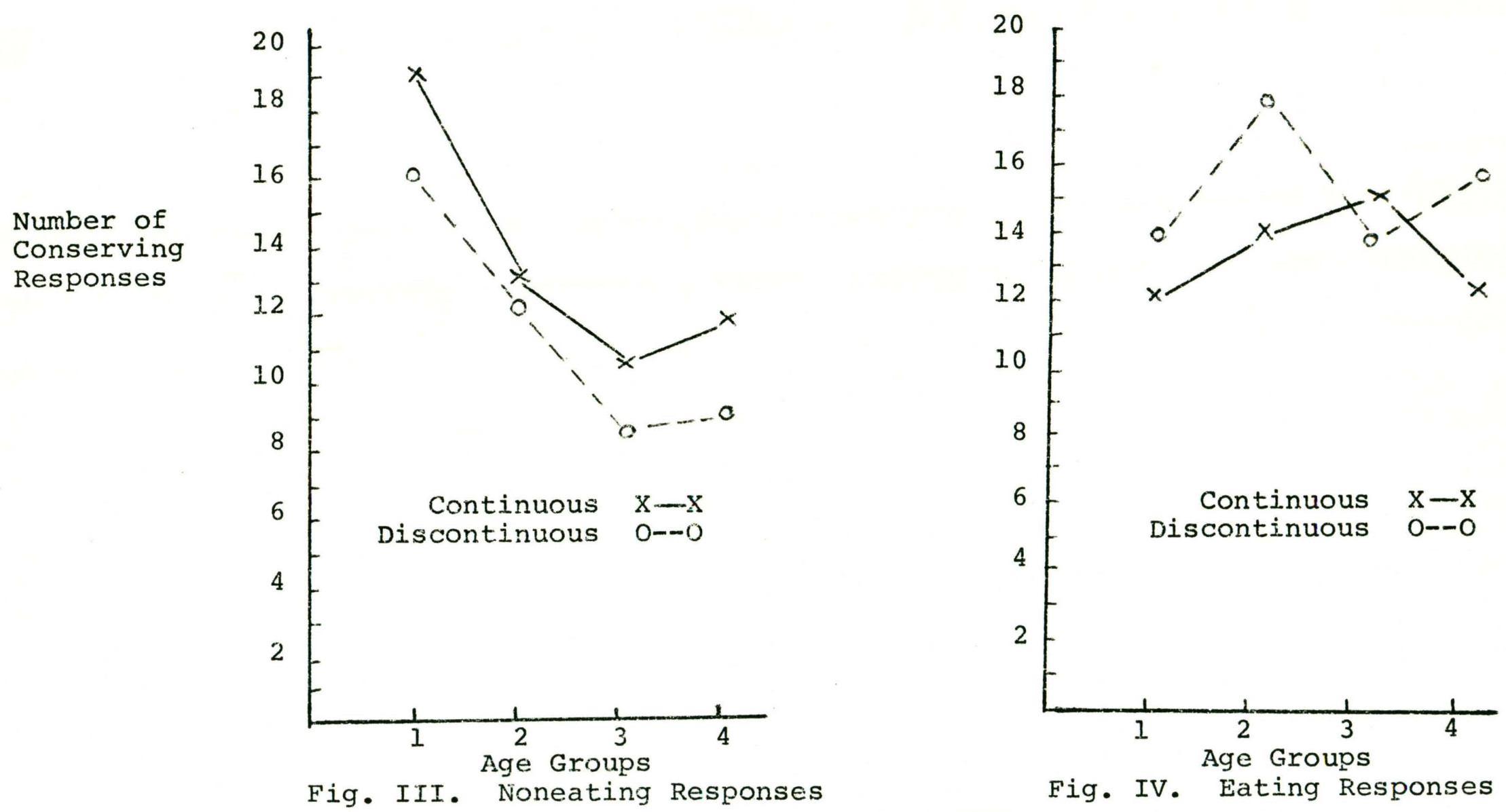

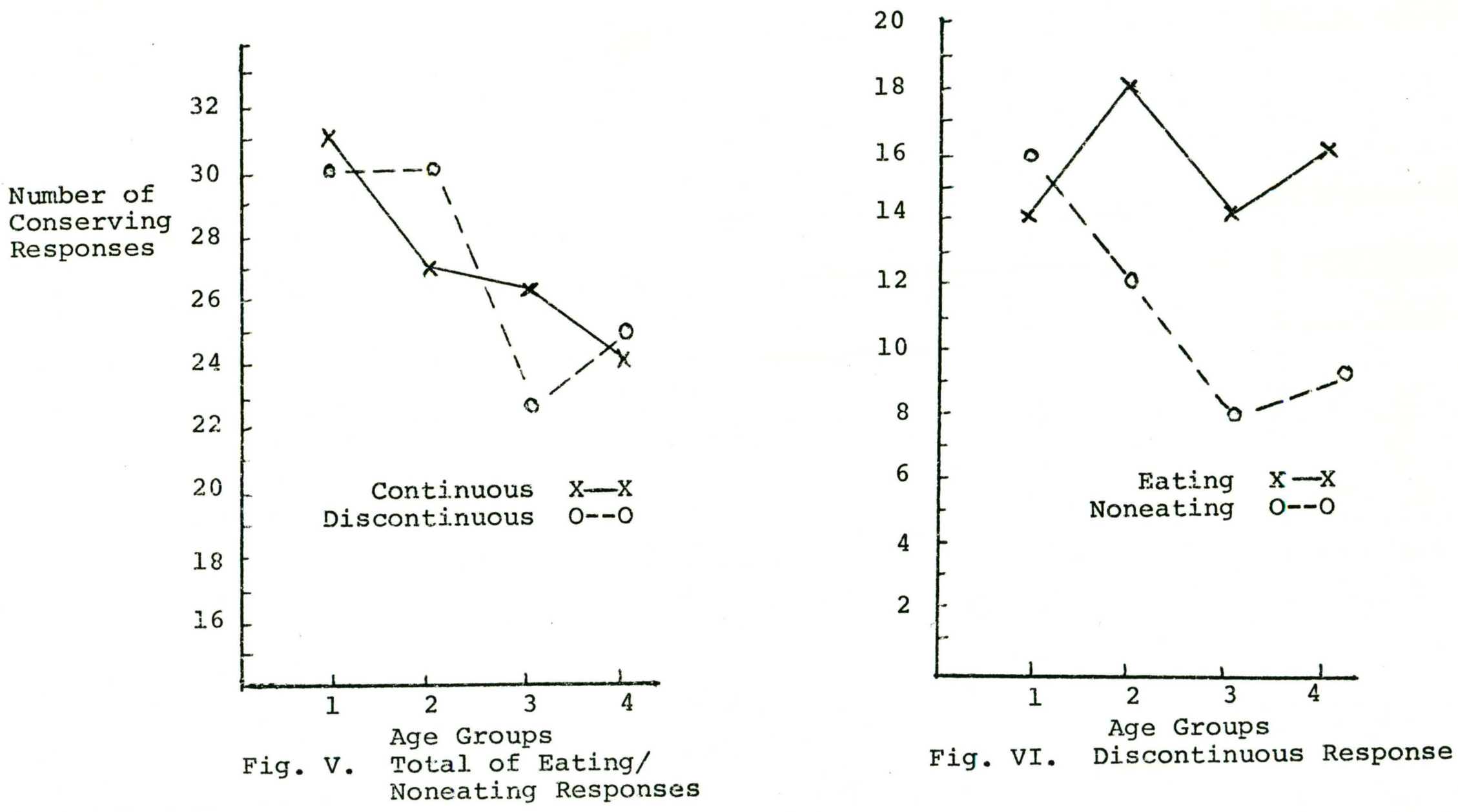


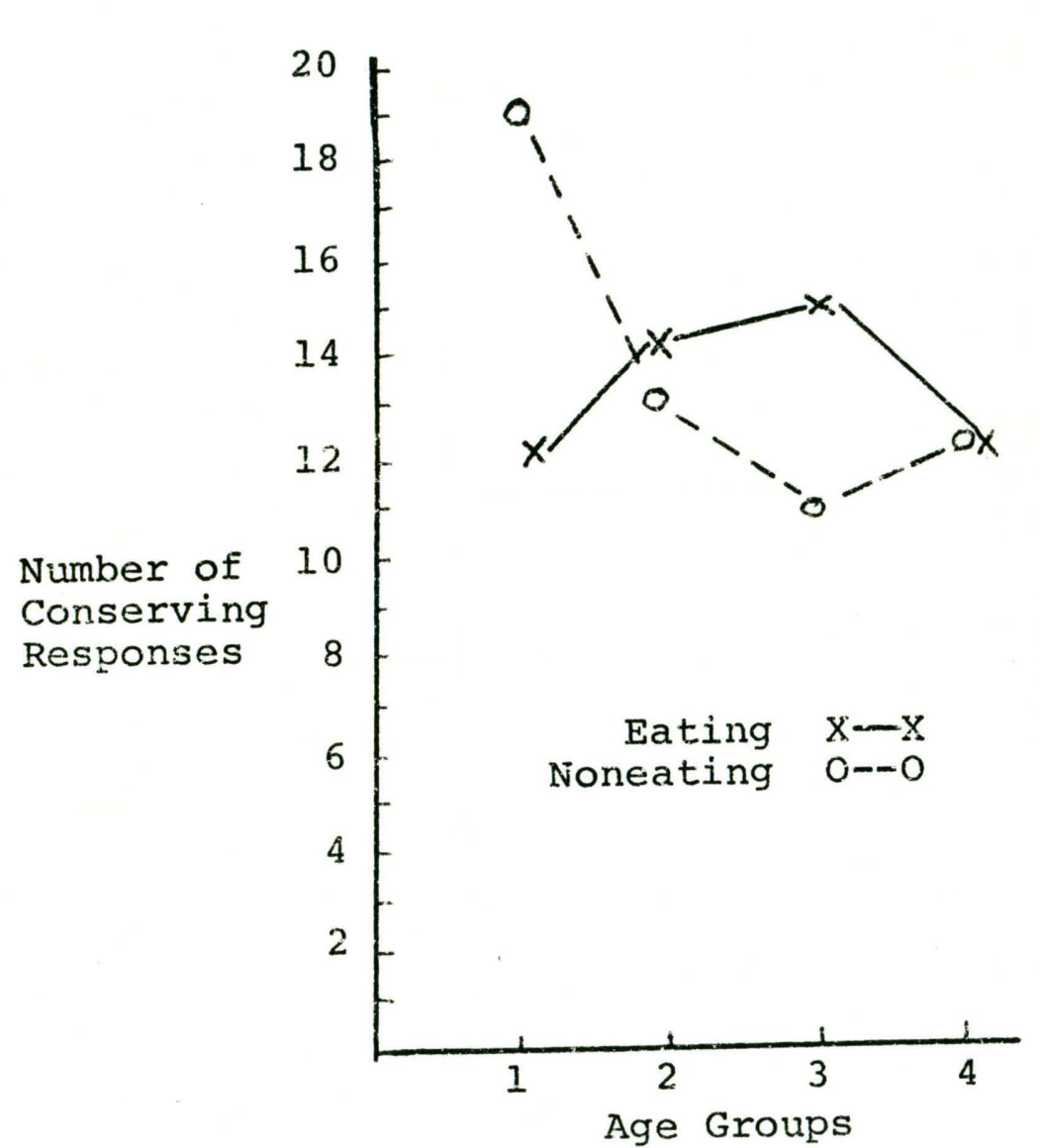

Fig. VII. Continuous Responses

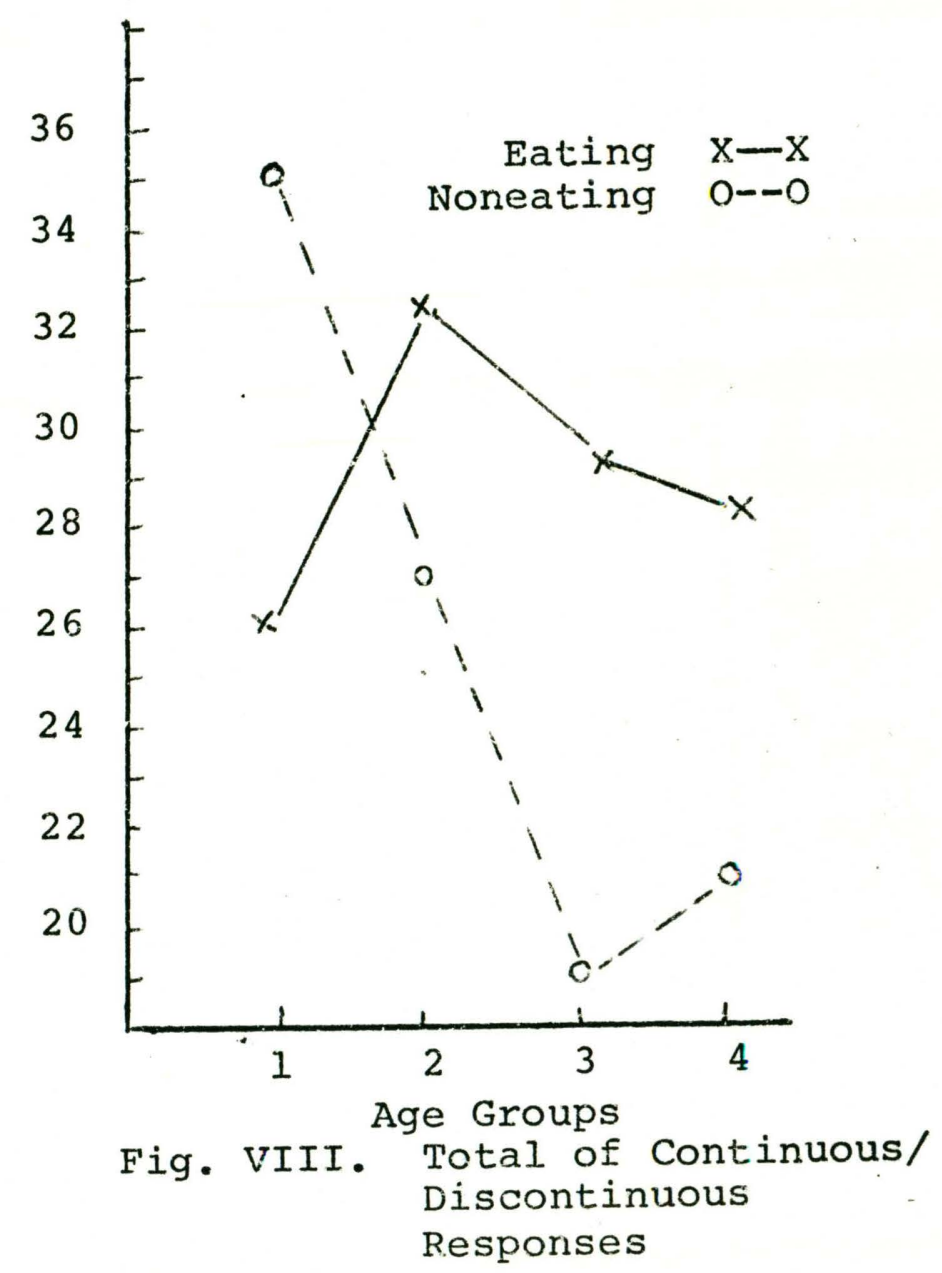


Number of Conserving Responses

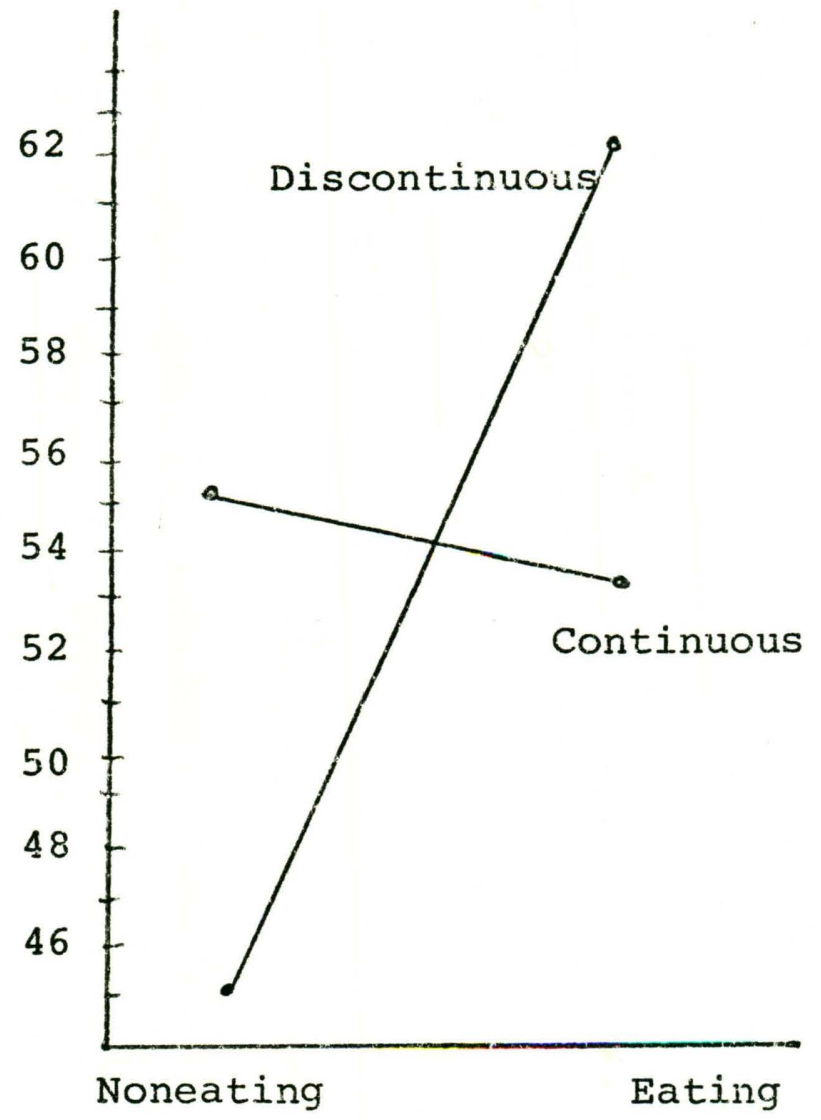

Figure IX. Interaction of Continuous/ Discontinuous and Eating/ Noneating Responses. 


\section{SUMMARY AND CONCLUSIONS}

The results of this study suggest that very young children were able to conserve on a particular task. This is evidenced by the performance of Group I on the continuous/ Noneating task and Group 2 on the Djscontinuous/Eating task. However the results do not seem to indicate that these children had a "fjrm" conservation concept since they did not conserve on any more than one task per age group. In this respect the findings are not as strong as those in the Mehler and Bever study where the conservation responses were very high and significant in both tasks.

Although the interaction of the Continuous/Discontinuous and Eating/Noneating categories was significant, there does not appear to be a consistent explanation for this observation. There were no significant main effects due to age, group, discontinuous/continuous, or eating/noneating.

Although this study did not show many significant results with very young children, some instances of conservation were found, and this experimenter feels that further study is warranted. Various refinements could be made in future studies. For instance, rather than taking the first response of the child, several presentations could be given to the child. In this way a better measure of whether an individual child was conserving could be obtained.

For testing conservation on a discontinuous task alone, M\&M's would probably be a better material. to use since most 
children are already familiar with them and like their taste. However, a different material would have to be used in the continuous task. Therefore, to permit, a measurement of conservation with the same material, M\&M's were not used in this study. With a large enough pool of subjects, M\&M's could be used and the effect of different materials could also be evaluated. 


\section{BIBLIOGRAPHY}

Bruner, J.S. Olver, R.R., Greenfield, P.M. et. at. Studies in Cognitive Growth. New York: Wiley, 1967.

DodwelI, P.C. "Children's Understanding of Number and Related Concepts." Canadian Journal of Psychology, $1960,14,191-205$.

Estes, B.W., "Some Mathematical and Logical Concepts in Children." Journal of Genetic Psychology, 1956, 83, 219-222.

Lovell, K., The Growth of Basic Mathematical and Scientific Concepts in Children. Philosophical Library: New York, 1961.

Mehler, L. and Bever, T.G., "Cognitive Capacity of Very Young Children," Science, 1967, 158, 141-142.

Piaget, J., The Child's Conception of Number. London Routledge \& Kegan Paul, 1952.

Piaget, J., "How Children form Mathematical Concepts." Scientific American, 1953, 189, No. 5, 74-79.

Piaget, J., Irhelder, B., and Szeminska, A. The Child's Conception of Geometry. New York: Basic Books, 1960.

Winer, B., Statistical Principles and Experimental Design. New York: McGraw Hill, 1962. 